\title{
Saúde, Empoderamento e Triangulação
}

\section{Health, Empowerment and Triangulation}

\section{Fernando Lefèvre}

Prof. Titular, Faculdade de Saúde Pública da USP.

E-mail: flefevreœusp.br

\section{Ana Maria Cavalcanti Lefèvre}

Pesquisadora do Centro de Controle de Doenças da Prefeitura de Município de São Paulo, Doutora pela Faculdade de Saúde

Pública da USP e Comissionada na Faculdade de Saúde Pública da USP.

E-mail: alefevreœusp.br

\section{Resumo}

A saúde no presente artigo é enfocada a partir de três pontos de vista: o ponto de vista do indivíduo, o ponto de vista do sistema produtivo e o ponto de vista técnico. Para o indivíduo, a saúde pode ser vista como uma sensação (de não doença, não dor, etc.); para o sistema produtivo, ela pode ser vista como um valor a ser oferecido num mercado privado e público de bens de saúde e para o técnico, como um poder, o poder de proporcionar saúde. A partir destes três pontos de vista, várias interrelações podem ser pensadas, exemplificando-se aqui quatro delas. Nesta teia de relações, a questão do empoderamento se revela importante, salientando-se, neste contexto, a importância de se considerar o indivíduo e/ou consumidor e/ou usuário como "elo mais fraco" e, portanto, mais carente de uma ação empoderadora.

Palavras-chave: Saúde; Empoderamento; Perspectivas. 
Abstract

In this article health is focused by three points of view: of the individual, of the productive system and of the technician. For the individual, health is viewed as a sensation (of non-disease, of no-pain, etc); for the productive system, health is viewed as a value to be offered in the private and public market; and for the technician, as a power to provide health.

From these three points of view, many interactions can be obtained. In the web of nteractions, empowerment is important, as the individual can be seen as the weakest actor.

Key Words: Health; Empowerment; Approach.

\section{Introdução: por uma visão ampliada da comunicação social em saúde}

Com vistas a expandir o campo da comunicação social em saúde, visando dotá-la de uma feição mais moderna ou até pós moderna, imaginamos pensá-la a partir de um triângulo (trata-se de uma escolha arbitrária: poderia ser qualquer outra figura geométrica) que articularia um sem número de relações de comunicação (de todo tipo: de dominação, subordinação, doutrinação, rebeldia, harmonia, complementariedade, diálogo, etc.) entre seus três pontos, aqui entendidos como pontos de vista, isto é, perspectivas e lugares e espaços sociais, que definiriam modos distintos de perceber, vivenciar, produzir, consumir saúde.

\section{Três Pontos de Vista}

Assim pensamos que, no mundo atual e particularmente entre nós brasileiros, a saúde é um ente que pode ser entendido a partir de três pontos de vista: do ponto de vista dos indivíduos (PVI), do ponto de vista do sistema produtivo(PVSP) e do ponto de vista técnico (PVT).

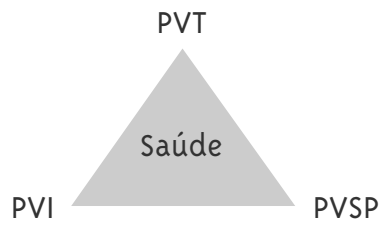

Do ponto de vista dos indivíduos, saúde pode ser vista como uma qualidade de um ou de uma parte de um corpo/mente de um indivíduo, ou de uma soma de indivíduos, percebida por estes indivíduos ou como bem estar, ou ausência de mal estar, ausência de doença, ausência de sintomas, ou como qualquer outro estado considerado saudável, com base em algum critério socialmente compartilhado, que os indivíduos podem ter, ser, estar, ou obter.

Deste ponto de vista, portanto, saúde pode ser vista como uma sensação: os indivíduos sentem que são saudáveis, com base em uma série de indicadores socialmente disponíveis (como raramente, ou nunca terem sido acometidos de doenças graves, estarem permanentemente dispostos para o trabalho, etc.). De forma semelhante, estes indivíduos estão sentindo-se 
saudáveis quando as sensações correspondentes, de base igualmente social, tem como referência um espaço de tempo mais delimitado ${ }^{1}$.

Por outro lado, os indivíduos obtém saúde pelo consumo, direto ou indireto, de algum tipo de produto ou serviço considerado, com base ou não em critérios técnicos, como produtor ou indutor externo de saúde ou de proteção contra doenças, tais como remédios, vitaminas, alimentos, vacinas, cirurgias, massagens e muitos outros (Lefèvre, 1991).

Do ponto de vista do sistema produtivo, saúde é um dos valores a ser reificado em mercadorias ou serviços, cujo uso ou consumo implica entrar na posse do valor consumido.

Este valor precisa ser impreciso, aberto, elástico (Lefèvre,1999) para que um vasto e indefinido lote de mercadorias e serviços, em permanente ampliação, possa dele se apropriar para, por seu intermédio, se vender no mercado.

De um ponto de vista técnico, a saúde pode ser vista como um tipo específico de poder ou autoridade, no sentido sociológico do termo (Bourdieu, 1982), que chamamos PPS, ou Poder de Proporcionar Saúde (Lefèvre, 1998 ), poder esse de que é investido um conjunto de profissionais ou especialistas para: conceituar saúde; prescrever saúde (comportamentos saudáveis); produzir tecnologia e ações, que, por sua vez, produzirão um "efeito" de saúde em indivíduos e populações e, finalmente, para atestar que uma dada pessoa ou comunidade é, ou está, saudável ou doente.

\section{Quatro Interrelações}

Estas três perspectivas dão lugar, como seria de se imaginar, a um sistema dinâmico de relações, onde os pontos de vista se interinfluenciam fortemente.

Discutiremos aqui, a título de exemplo, quatro interrelações possíveis entre os pontos de vista do indivíduo (PVI), do técnico (PVT) e do sistema produtivo (PVSP).

\section{Primeira interrelação (PVI ↔PVSP): existe uma "mais saúde" como um desejo insuflado pelo sistema produtivo}

No que toca à saúde, não seria equivocado, pensamos, dizer que os indivíduos são, entre outras coisas, feixes de vontades ou desejos inconscientes, a serem mobilizados e manipulados pelo sistema produtivo.

Como assinalado alhures (Lefèvre, 1997), a saúde pode ser entendida, também, como um desejo, não no sentido de que as pessoas espontaneamente desejem saúde, mas sobretudo como um querer, digamos virtual, a ser, no contexto histórico das sociedades de consumo atuais, insuflado, organizado, manipulado de fora, pela publicidade enquanto "braço simbólico" do sistema produtivo.

Podemos chamar esta saúde desejada de maissaúde ou saúde elástica, para distingui-la da saúde simplesmente, entendida esta última como uma espécie de ponto zero, abaixo do qual o indivíduo está doente.

Exemplos típicos de "mais saúde" podem ser representados pelo assim chamado "uso recreativo" de remédios tipo Viagra e pelas "plásticas estéticas" e afins (ambos, comportamentos largamente difundidos, hoje, entre nós, brasileiros) que não são, explicitamente, saúde negativa, isto é "não doença”, mas um acréscimo ou surplus de saúde, em indivíduos saudáveis.

Ser ou estar saudável não implicaria então apenas em não sentir-se doente, mas,também, positivamente, em sentir-se belo, poderoso, viril, sensual, eternamente jovem, etc.

É importante notar que, na história da humanidade, estes desejos, em si mesmo, nada têm de novo; o que muda, hoje, é que eles passam a ser administrados por profissionais de saúde (médicos, nutricionistas, psicólogos, etc.), na qualidade de ações, serviços, produtos, processos embasados em ciência e tecnologia.

Como conseqüência, impulsos outrora carregados de culpa, ou pensáveis apenas no plano da fantasia, são hoje legitimados, passando a ser vistos como coisas saudáveis, ou seja, não apenas como aspirações perfeitamente admissíveis, mas também, mais maquiavelicamente, como estados sem os quais os indivíduos passam a ser vistos como quase-doentes: homens acima da faixa dos 5o, cuja performance sexual naturalmente decresce, passam sutilmente a se sentirem quase-doentes, sendo instados pela publicida-

\footnotetext{
1 Ver a respeito a diferença entre ser e estar saudável (Lefèvre F, 1999). Em paralelo, seria curioso saber se, ou como, este sentimento de
} estar com saúde se expressa nas pessoas que vivem em culturas cujos idiomas não permitem diferenciar claramente "ser" de "estar". 
$\mathrm{de}^{2}$ a consultarem seu médico, com vistas a restabelecer sua "saúde sexual"; por sua vez, mulheres na mesma faixa etária, são instadas, pela publicidade e pela medicina, a reporem no organismo os hormônios que naturalmente não produzem mais, sob pena de adoecerem de menopausa.

Este querer sempre mais ou desejo infinito, viabilizado pela $C \& \mathrm{~T}$ e mercadologicamente instrumentalizado pela propaganda e marketing, encontra terreno fértil e mesmo privilegiado no campo da saúde.

Assim, cabe colocar, pensamos, que a mais saúde representa um estágio avançado e bem sucedido do processo histórico da mercantilização da vida em geral, condição necessária para o bom funcionamento do modo de produção do capitalista

\section{Segunda interrelação (PVI $\leftrightarrow$ PVT): hoje, para o indivíduo, não basta se sentir saudável, é preci- so um atestado de saúde}

Nos dias atuais, em muitas circunstâncias, em função do chamado avanço do conhecimento científico sobre o corpo humano normal e patológico, os indivíduos comuns não estão em condições de saber se são/ estão com saúde, já que não basta (ou pode ser enganoso e até perigoso) sentirem-se saudáveis, bem dispostos para o viver o dia a dia e para o trabalho, já que, pelo fato de serem seres humanos comuns e não profissionais de saúde, não tem PPS, ou seja, poder ou autoridade, dado pelo conhecimento científico, para saber se são / estão ou não saudáveis.

Estes indivíduos, em muitas circunstâncias, para saber se são ou estão saudáveis, necessitam então de um atestado.

Este atestado pode ser formal/legal (para fins de emprego, dispensa de trabalho,etc.) ou para consumo individual, mas é sempre uma informação absolutamente necessária para que os indivíduos possam viver o dia e para se programarem para o futuro imediato ou remoto.

Acontece que, dadas as contingências da vida diária nos grandes centros, as dificuldades de todo tipo para acessar os sistemas de saúde, a crise de confia- bilidade na tecnologia médica e no tirocínio médico e mesmo a mais que legítima vontade dos indivíduos de gerirem, com seus recursos próprios, a sua saúde, acaba ficando impossível e mesmo indesejável estar a todo momento obtendo atestados confiáveis de saúde. Mas, por outro lado, esta impossibilidade leva os indivíduos de hoje a se sentirem larga e crescentemente inseguros em relação à sua saúde.

Além disso, dado o avanço científico e tecnológico exponencial da chamada "medicina diagnóstica", criou-se, em sociedades como a brasileira, com os conhecidos padrões de desigualdade de distribuição de renda, um acesso correspondentemente desigual aos meios de obter "atestados de saúde". Uma reportagem recente da revista Veja (2003) sobre a concorrência entre dois "gigantes" da medicina diagnóstica brasileira ilustra bastante bem esta situação, na medida em que indica uma tendência a "nivelar por cima”os padrões de consumo de serviços médicos desejáveis.

Terceira interrelação: (PVI $\leftrightarrow$ PVT): há uma dificuldade estrutural na comunicação entre as autoridades sanitárias/profissionais de saúde e a população/usuários/clientes/consumidores que decorre de um conflito entre a lógica sanitária, que preside as me nsagens $e$ os sentidos emanados do campo sanitário, e a lógica do senso comum, que preside as mensagens e os sentidos emanados do senso comum. ${ }^{3}$

População e profissionais de saúde falam e atuam sobre a saúde e doença de dois lugares ou espaços sociais bastante distintos.

Esquematicamente, podemos dizer que os profissionais de saúde falam e atuam sobre saúde/doença a partir dos Serviços (hospitais, Centros de Saúde, clínicas privadas) e/ou das Universidades, e/ou do Aparelho de Estado ligado à Saúde (secretarias de saúde, Ministério da Saúde, etc).

Já as pessoas falam e atuam sobre a saúde a partir das suas casas, de seus escritórios, de suas fábricas, de seus serviços e até da rua.

\footnotetext{
2 A este respeito vale mencionar um, folheto envolvendo o tema da chamada "disfunção eréctil" colhido pelo autor em 2005 , em uma prestigiosa unidade de saúde de São Paulo, pelo seu caráter exemplar, que mereceria todo um estudo sobre a "intenção medicalizante" e o uso descarado e por vezes grosseiro de técnicas de "sedução comunicativa".

30 texto desta quarta interrelaçao encontra-se, em parte, no livro "Promoção de Saúde. A negação da negação" (Lefèvre F e Lefèvre, 2004)
} 
Nesse sentido, é fácil perceber um poderoso conflito, na medida em que sendo a saúde e a doença entendidas, de acordo com a representação social dominante na época atual, como um assunto técnico/científico, a fala profissional é uma fala legal, socialmente autorizada (Bourdieu, 1982), porque vinda de um espaço técnico científico (Santos, 1996), enquanto a fala do indivíduo comum é uma fala leiga, desautorizada, prosaica, ilegal, deseducada porque proveniente de um espaço vivencial, da cotidianidade.

Sendo assim, não há diálogo possível entre as partes, mas apenas uma prática discursiva e comportamental regida por relações assimétricas de mando/ obediência; prescrição/cumprimento da prescrição, podendo estas relações serem mais autoritárias ou mais gentis (Wilson, 2003), ou menos "participativas", ou "educativas", ou “cooperativas", o que não muda em nada sua natureza estruturalmente assimétrica.

Mas um importante componente vem complicar esta assimetria estrutural, deixando, em tese, espaço para o seu questionamento.

Com efeito, o profissional fala científica/tecnicamente sobre um objeto tecnocientífico (a saúde/doença), mas este objeto sobre o qual ele fala, com autoridade, se por um lado lhe pertence como objeto científico, de estudo e intervenção, por outro lhe é radicalmente exterior, implicando, além disso, em alteridade, na medida em que pertence, enquanto sentimento de corporiedade (Turner, 1989), sensação física e emocional, objeto de direito, locus de autonomia, à pessoa, ao indivíduo dono de seu corpo. Isto é, a saúde e a doença são objetos técnicos/científicos e de cientistas/ técnicos mas, também e contraditoriamente, atributos e condições de sujeitos humanos.

Este conflito dá nascimento, entre outras coisas, ao campo da Bio Ética como um espaço de reflexão e de prática sobre esta problemática (Fortes e Zoboli, 2004)

Mas, se por um lado o fato do corpo e da corporiedade permitirem, em tese, aos indivíduos comuns reapropriarem-se, pelos menos em parte, como sujeitos, da sua saúde e da sua doença, ainda sobra amplo espaço para a manutenção e reprodução das relações de dominação anteriormente mencionadas.
Temos uma (entre muitas) interessante ilustração disto, num trabalho realizado com estudantes de medicina sobre as razões por eles alegadas para a escolha do curso de medicina (Ignarra, 2002), quando parte dos estudantes afirmam que sua escolha pelo curso se deve ao fato da medicina lidar com a vida.

Ora, esta representação social, lida de outro ângulo, pode gerar o seguinte sentido (com seu correspondente efeito prático): você indivíduo comum deve me obedecer porque eu, na qualidade de médico, tenho a chave da sua vida e, conseqüentemente, da sua morte nas minhas mãos técnicas, o que implica que o exercício da sua rebeldia ou da sua autonomia como sujeito, ainda que represente uma possibilidade concreta e até um direito pode, na prática, significar a sua condenação à morte ou ao sofrimento.

Quarta interrelação: (PVSP $\leftrightarrow$ PVT $\leftrightarrow$ PVI): numa sociedade de consumo, a saúde tende a se transformar, progressivamente, em mercadoria/serviço gerada pelo sistema produtivo; mas ela é, também, ao mesmo tempo, um objeto tecnocientífico subordinado ao conhecimento das ciências da saúde, sob o controle e de posse dos profissionais de saúde. Isto gera uma situação comunicativa complexa e uma importante tensão comunicacional, com a presença de dois sujeitos emissores das mensagens de saúde falando, frequentemente na mesma mensagem, de dois lugares distintos, para o mesmo destinatário, que pode ser tanto o paciente, quando o consumidor, quanto as duas coisas reunidas.

O indivíduo sente dor, o sistema produtivo vende alívio da dor em comprimidos e o profissional de saúde avalia, qualifica, define a natureza da dor e propõe, em função disso, uma intervenção técnica diante da dor.

Há um caminho real, conhecido de todos, para a adequada comunicação entre estas três esferas: o indivíduo que sente a dor; comunica este sentimento ao profissional de saúde, que qualifica e contextualiza esta informação para, em seguida, indicar um tratamento que pode, eventualmente, consistir em prescre- 
ver um medicamento disponível no mercado para ser consumido pelo indivíduo.

Mas este é apenas um dos caminhos comunicacionais possíveis, o da lógica sanitária, de natureza tecno científica, que precisa ser socialmente contextualizado, entendendo-se e admitindo-se que ele coexiste em relações de conflito, cooperação, harmonia, competição, etc., com caminhos comunicacionais alternativos.

Por exemplo, com o caminho que começa com o desejo/necessidade do laboratório farmacêutico x de incrementar a venda de seu analgésico e que segue com a comunicação e o encaminhamento deste desejo para uma agência de propaganda, que funciona como um apêndice ou, na formulação gramsciana, como um intelectual orgânico do sistema produtivo, e que organiza e viabiliza este desejo num discurso eficaz destinado ao público objeto.

Este público, digamos, na situação de expectador de televisão, é exposto ao estímulo, "cai na rede" (ou seja, presta atenção na mensagem) e a decodifica do modo desejado (e induzido na mensagem) que é o de identificar-se com o simulacro iconizado na publicidade, o que permite a viabilização da lembrança do nome do analgésico; com isso está fechada a cadeia de comunicação padrão na área da saúde, quando o principal interessado e desencadeador do processo é o sistema produtivo.

Mas fica claro que este segundo exemplo representa uma violação do caminho real, na medida em que ele "bypassa" o ponto de vista técnico, estabelecendo uma relação direta (e promíscua) entre o ponto de vista do sistema produtivo e o ponto de vista do indivíduo, configurando-se, no campo da saúde/doença, uma simples relação: produtor-consumidor, deixando a dor de ser vista como uma questão necessariamente técnica, da alçada e sob o controle do conhecimento científico sobre saúde/doença

\section{Desdobramentos do Modelo Triangular para o Processo de Empoderamento}

O presente modelo triangular pode ser útil para entender a comunicação social em saúde, no contexto da sociedade brasileira atual, como uma situação altamente complexa, decorrente das interações entre estes três grandes sujeitos comunicacionais, que são o conhecimento científico, com a sua perspectiva técnica, o sistema produtivo de bens e serviços de saúde, com a sua perspectiva eminentemente mercadológica e o indivíduo do senso comum, o portador da saúde e da doença ou o dono do corpo onde acontece a saúde e a doença.

Para o pensamento sanitário que se guia pelos princípios da Promoção de Saúde há um posicionamento político diante desta problemática que nos parece obrigatório e que consiste na tarefa de empoderar o elo mais fraco deste triângulo, que é justamente o ponto de vista do indivíduo.

De outro parte, o profissional de saúde também precisaria ser empoderado, na medida em que talvez não esteja sempre devidamente consciente de que hoje, entre nós brasileiros, o simples fato de ser profissional de saúde não dá a este sujeito nenhuma garantia definitiva de que a sua mensagem seja entendida e adotada.

Uma grande questão fica, no entanto, no ar: hoje, nas atuais circunstâncias, seguramente, o setor publico, estatal, não consegue dar conta, sozinho desta tarefa empoderadora. Mas, por outro lado, os espaços públicos não estatais, como as Organizações Não Governamentais, o (mal) chamado Terceiro Setor, as ainda frágeis instâncias responsáveis pelo (também mal chamado) controle social, estão ainda longe de representarem espaços alternativos suficientemente consistentes.

Sabemos hoje o que fazer (empoderar) e quem deve ser empoderado (a população, antes de mais nada e também o profissional de saúde), mas não temos muito claro como, onde e com quem fazer.

Para avançar, ainda que relativamente, no enfrentamento desta problemática, um dos começos possíveis seria, nos parece, a realização de pesquisas empíricas que pudessem trazer a luz as representações sociais dos profissionais e dos individuos. Estas representações poderiam constituir uma significativa matéria prima que ajudaria muito no desenho do conteúdo e da forma destes processos empoderadores. 


\section{Referências}

BOURDIEU, P; PASSERON, J. C. A reprodução. Rio de Janeiro: Francisco Alves, 1982.

FORTES, P.; ZOBOLI, E. Bioética e promoção da saúde. In: LEFÈVRE, F.; LEFÈVRE, A. M. C. Promoção de saúde: a negação da negação. Rio de Janeiro: Viera e Lent, 2004.

IGNARRA, R. Medicina: representação de estudantes sobre a profissão. São Paulo, 2002. Tese (Doutorado em Saúde Pública) - Faculdade de Saúde Pública da Universidade de São Paulo.

LEFÈVRE, F. Mitologia sanitária. São Paulo: Edusp, 1999.

LEFÈVRE, F. O medicamento como mercadoria simbólica. São Paulo: Cortez, 1991.
LEFÈVRE, F. El poder de proporcionar salud. Fermentum, v. 8, n. 22, 1998.

LEFÈVRE, F. Saúde, este obscurso objeto de desejo. Saúde e Sociedade, São Paulo, v. 6, n.1, 1997.

Lefèvre F; Lefèvre. AMC. Promoção de Saúde. a negação da negação. Rio de Janeiro, Viera e Lent, 2004

Revista Veja 30 de abril de 2003.

Santos M. Técnica como espaço e tempo. São Paulo, Hucitec, 1996.

Turner, B. El cuerpo y la sociedad. México. Fondo de Cultura, 1989.

Wilson HV. Paradoxical porsuits in child health nursing practice: discourse of scientific mothercraft. CPH 13(3), 2003.

Recebido em: 03/02/2004

Reapresentado em: 14/05/2004

Aprovado em: 08/06/2004

38 Saúde e Sociedade v.13, n.2, p.32-38, maio-ago 2004 